\title{
ALESSANDRA MARANGONI, Laforgue et le Sacré-Cœur, "Romantisme" 185 (3/2019)
}

\section{Mario Richter}

\section{OpenEdition}

\section{Journals}

\section{Edizione digitale}

URL: https://journals.openedition.org/studifrancesi/32088

DOI: 10.4000/studifrancesi.32088

ISSN: 2421-5856

\section{Editore}

Rosenberg \& Sellier

\section{Edizione cartacea}

Data di pubblicazione: 1 août 2020

Paginazione: 430

ISSN: 0039-2944

\section{Notizia bibliografica digitale}

Mario Richter, "Alessandra maRAngon, Laforgue et le Sacré-Cœur, "Romantisme" 185 (3/2019)», Studi

Francesi [Online], 191 (LXIV | II) | 2020, online dal 01 septembre 2020, consultato il 18 septembre 2021. URL: http://journals.openedition.org/studifrancesi/32088 ; DOI: https://doi.org/10.4000/studifrancesi. 32088

Questo documento è stato generato automaticamente il 18 septembre 2021.

\section{(c) $($ ) $(9)$}

Studi Francesi è distribuita con Licenza Creative Commons Attribuzione - Non commerciale - Non opere derivate 4.0 Internazionale. 


\title{
ALESSANDRA MARANGONI, Laforgue et le Sacré-Cœur, "Romantisme" 185 (3/2019)
}

\author{
Mario Richter
}

\section{NOTIZIA}

ALESSANDRA MARANGONI, Laforgue et le Sacré-Cœur, “Romantisme” 185 (3/2019), pp.

108-121.

1 Articolato in cinque sezioni («Une question d'édition», «Le Sacré-Cœur: littérature, religion, chanson...», «De litanie en litanie: du Baudelaire en Laforgue», «Économie du recueil: des additions fort notables», «De Michelet à Huysmans»), questo articolo mette in chiara luce la genesi e il particolare significato storico-letterario di una poesia inserita ne Les Complaintes, quella intitolata Complainte-litanies de mon Sacré-Cœeur, testo che si rivela anche utile a orientare una proficua lettura dell'intera raccolta. La studiosa prende le mosse dalla constatazione che Laforgue - apprestandosi a pubblicare nel 1885 Les Complaintes già approntate l'anno precedente per essere consegnate all'editore Léon Vanier ma rinviate per mesi - inserì all'ultimo momento le Litanies de mon triste cœur, vecchia poesia già prevista per la precedente raccolta Le Sanglot de la terre (1882), modificandone il titolo con Complainte-litanies de mon Sacré-Coeur. Il testo, inizialmente concepito nei termini di un autobiografico "triste cœur" (con variante manoscritta "pauvre cœur") di gusto romantico e decadente, risulta in tal modo orientato verso un palese e blasfemo distacco ironico. Si tratta dunque del preciso momento in cui viene ad attuarsi quello che Sergio Solmi, in una sua importante introduzione alle Poesie complete di Laforgue (1966), chiamò «rovesciamento dell'angoscia cosmica in disincanto lirico-ironico». Nello specifico, la definitiva variante su cui si appunta Alessandra Marangoni sembra essere chiaramente dovuta alla pubblicazione e al successo, nei primi mesi del 1885, delle Déliquescences di Adoré Floupette, efficace caricatura della 
moda decadente della quale Laforgue poteva apparire un'evidente espressione e un facile bersaglio. L'argomentazione critica sulla quale si dipana, con ordine ed eleganza, l'articolo è appunto concentrata, essenzialmente, sulla sostituzione di "mon triste cœur" con "mon Sacré-Cœur" e trova sostegno in un ricco, puntuale e persuasivo percorso attraverso le diverse vicende dissacranti o riparatrici che, soprattutto nel secondo Ottocento, riguardano in Francia il "Sacré-Cœur" anche in rapporto alle vicende della questione romana. Una larga parte della popolazione francese rimasta fedele ai princìpi religiosi e al Papato oppose infatti via via agli effetti rivoluzionari fino alla Comune e ai connessi dileggi anticristiani un'accesa devozione riparatrice al Sacro Cuore di Gesù, alla cui origine era riconosciuta con particolare credito la figura della seicentesca monaca francese, amata e vilipesa, Marguerite-Marie Alacoque. Contro le irrisioni e le parodie provocate da una crescente secolarizzazione o esplicita scristianizzazione della società politico-culturale del tempo si giunse a erigere sulla parigina butte de Montmartre, con intento espiatorio, la famosa imponente basilica dedicata appunto al "Sacré-Cœur". S'intende che Laforgue, prima devoto e poi scettico, nelle Complaintes milita dalla parte della parodia, rivolgendosi in particolare alle popolari canzoni cattoliche in voga all'epoca. In questo, come bene illustra l'A. con vari esempi, il poeta trovava ispirazione e incoraggiamento in alcuni fra i maggiori intellettuali, scrittori e poeti del suo tempo quali Flaubert, Baudelaire, Verlaine, Michelet, Hello e Huysmans. 